\title{
The Text Effect: Stress Management and Resiliency Training Pilot for Resident Physicians
}

Jane Nathan, PhD; Laura McCray, MD, MSCE; Nathalie Feldman, MD

BACKGROUND AND OBJECTIVES: Burnout is common among resident physicians. Studies show that those who engage in stress management and mindful practice have improved empathy and lower rates of mood disturbance. This study piloted a program entitled Stress Management and Resiliency Training for Residents (SMART-R) with Family Medicine (FM) and Ob-Gyn residents at an academic medical center.

METHODS: The 6-hour SMART-R program, which teaches relaxation strategies, stress awareness, and adaptive coping, was mandatory for all years of residency and delivered in three 2-hour sessions during protected didactic time. Interested residents received a weekly phone text message with mindfulness and resiliency reminders to enhance practice between sessions. We measured burnout, empathy, perceived stress, mindful attention awareness, mind body practices, and program satisfaction.

RESULTS: There were 14 matched pre/post surveys (six FM, eight Ob-Gyn), of which 10 (five FM; five Ob-Gyn) opted to receive weekly texts. Empathy, stress, and burnout remained stable over time. Those who received the weekly texts showed a significant increase in mindful attention awareness and trended toward lower perceived stress compared to those who did not receive texts. Half of those surveyed felt the training should be mandatory and $71 \%$ would recommend it to colleagues. While $93 \%$ thought it was important to know the current research on mind-body medicine to guide patients, only $29 \%$ felt they knew much about this.

CONCLUSIONS: This study demonstrated the positive impact a 6-hour stress management and resiliency intervention can have on resident physicians. Unlike other studies that have shown decreased empathy and increased stress and burnout over time, these features remained stable over the academic year. Weekly text reminders supported the training and suggest potential benefit to enhance stress management training for medical professionals.

(Fam Med. 2021;53(2):139-44.)

doi: 10.22454/FamMed.2021.847102
$\mathbf{R}$ esident physician burnout is an important problem, with $50 \%-75 \%$ experiencing burnout at some point in training. ${ }^{1}$ Burnout, a work-related phenomenon, includes emotional exhaustion, depersonalization, and a low sense of personal accomplishment. ${ }^{2}$ Research shows that burnout leads to decreased empathy, ${ }^{3}$ higher rates of medical error, ${ }^{4-6}$ increased anxiety and depression, ${ }^{7}$ and higher rates of suicide. ${ }^{8}$ The Accreditation Committee for Graduate Medical Education (ACGME) has mandated that wellness curricula be incorporated into resident training and have asked institutions to investigate evidencebased programs. ${ }^{9}$ Research is limited, but studies show that self-care and meditation are beneficial ${ }^{10}$ and engagement in stress management techniques result in lower perceived stress, improved emotional exhaustion and depersonalization, ${ }^{11}$ and greater empathy. ${ }^{12-15}$

We piloted the Stress Management and Resiliency Training for Residents (SMART-R) in Obstetrics/ Gynecology (Ob-Gyn) and Family Medicine (FM) residents at a University medical center. SMART-R, delivered in three 2-hour sessions, was developed by and for resident

From the Department of Family Medicine (Drs Nathan and McCray), and Department of Obstetrics and Gynecology (Dr Feldman), Larner College of Medicine at the University of Vermont, Burlington, VT. 
physicians at Massachusetts General Hospital (MGH). ${ }^{16}$ Sessions include exercises that elicit the relaxation response, promote stress awareness, and encourage adaptive coping. MGH piloted SMART-R with postgraduate year 1 (PGY1) residents between June 2014 and January 2015. They found increased emotional exhaustion and depersonalization over time with other variables stable (empathy, perceived stress, mindfulness). ${ }^{16}$

We delivered SMART-R across PGY-1, 2, 3, and 4, hypothesizing similar if not improved results to MGH. We additionally piloted an optional weekly, curriculum-based phone text message between sessions to support practical application of the training. While there has been some literature on self-guided phone apps to improve mindfulness in resident physicians,${ }^{17}$ to our knowledge this is the first study to pilot phone text messaging to supplement this kind of intervention practice.

\section{Methods}

Procedures

Our institutional review board approved this study. A Benson-Henry Institute for Mind Body Medicine (BHI)-certified SMART healthcare practitioner delivered SMART-R in three 2-hour blocks (October 2017, January 2018, May 2018) during protected didactic time. Participation was mandatory unless work obligations precluded attendance. A total of 12 Ob-Gyn and 20 FM residents were enrolled in the program but due to clinical obligations and scheduling conflicts not all residents attended every session (Table 1).

Six FM (three PGY-1; one PGY-2; two PGY-3) and eight Ob-Gyn residents (three PGY-1; two PGY-2; one PGY-3; two PGY-4) completed fourteen matched pre-and postsurveys. Eight attended all sessions, four attended two, and two attended one. Of the 14 residents who initially elected to receive texts, 10 (five FM; five Ob-Gyn) completed pre- and posttests and are included in this analysis. Texts, sent once per week for 28 weeks, were designed by the certified SMART practitioner and included brief curriculum-supported suggestions for easily applied relaxation exercises and reminders to practice mindful awareness, gratitude, acceptance, self-care, and adaptive coping.

\section{Measures}

In addition to postqualitative surveys, pre/postquestionnaires, chosen to be consistent with similar studies, were administered around the training and included Mindful Attention Awareness Scale $;{ }^{18}$ Perceived Stress Scale-10 ${ }^{19}$ Perspective Taking subscale Interpersonal Reactivity Index (empathy) $;{ }^{20}$ and Maslach Burnout Inventory-2 Item (emotional exhaustion; depersonalization). ${ }^{21}$

\section{Results}

Paired $t$ tests found no score differences between specialties, or as a full group on any outcome measure (Table 2). Residents began with slightly lower mindful attention awareness compared to adult norms, which remained stable fall to spring $(P=.87)$. Empathy/perspective scores, initially slightly above college student norms, also remained stable $(P=.69)$. Perceived stress followed suit, initially endorsed at moderate levels and stable over time $(P=.86)$. Moderate emotional exhaustion and depersonalization also remained stable over time ( $P=.82 ; .08$, respectively).

Except for the text effect, there were no significant changes on any of the comparison variables on ANOVAs $(P>.05)$. There was however, a statistically significant interaction between texting and mindful attention awareness. Specifically, mindful attention awareness increased fall to spring for those who received texts versus a decrease in score for those who did not $(F[1,12]=5.94, P=.03$; Figure 1). Perceived stress followed a similar trend: those receiving texts tended to have lower perceived stress by spring compared to an increase

Table 1: Demographics and Attendance: Full Sample, Pre/Postmatched Sample, and Matched Text Sample

\begin{tabular}{|c|c|c|c|c|c|c|}
\hline & \multicolumn{2}{|c|}{ Full Sample ( $\mathrm{N}=32)$} & \multicolumn{2}{|c|}{ Matched Pre/Post ( $n=14)$} & \multicolumn{2}{|c|}{$\begin{array}{l}\text { Matched Pre/ } \\
\text { Posttext }(n=10)\end{array}$} \\
\hline & FM $(n=20)$ & $\begin{array}{l}\text { Ob-Gyn } \\
(n=12)\end{array}$ & FM $(n=6)$ & $\begin{array}{c}\text { Ob-Gyn } \\
(n=8)\end{array}$ & FM $(n=5)$ & $\begin{array}{l}\text { Ob-Gyn } \\
(n=5)\end{array}$ \\
\hline Gender (male/female) & $9 \mathrm{M} ; 11 \mathrm{~F}$ & $1 \mathrm{M} ; 11 \mathrm{~F}$ & $2 \mathrm{M} ; 4 \mathrm{~F}$ & $1 \mathrm{M} ; 7 \mathrm{~F}$ & $1 \mathrm{M} ; 4 \mathrm{~F}$ & $0 \mathrm{M} ; 5 \mathrm{~F}$ \\
\hline Number of PGY-1 residents & 6 & 3 & 3 & 3 & 2 & 2 \\
\hline Number of PGY-2 residents & 7 & 3 & 1 & 2 & 1 & 0 \\
\hline Number of PGY-3 residents & 7 & 3 & 2 & 1 & 2 & 1 \\
\hline Number of PGY-4 residents & & 3 & & 2 & & 2 \\
\hline \multicolumn{7}{|l|}{ Session Attendance } \\
\hline October session 1: full sample: $63 \%$ & $65 \%$ & $58 \%$ & $100 \%$ & $75 \%$ & $100 \%$ & $80 \%$ \\
\hline January session 2: full sample: $81 \%$ & $90 \%$ & $67 \%$ & $83 \%$ & $63 \%$ & $80 \%$ & $40 \%$ \\
\hline May session 3: full sample: $47 \%$ & $40 \%$ & $58 \%$ & $100 \%$ & $75 \%$ & $100 \%$ & $80 \%$ \\
\hline
\end{tabular}

Abbreviations: FM, family medicine; Ob-Gyn, obstetrics and gynecology; M, male; F, female. 
Table 2: Questionnaire Means by Specialty and Full Group ( $\mathrm{N}=14)$

\begin{tabular}{|c|c|c|c|}
\hline Survey & Pre-M & Post-M & $P$ \\
\hline \multicolumn{4}{|l|}{ MAAS ${ }^{a}$} \\
\hline Full & 3.5 & 3.5 & .87 \\
\hline FM & 4.0 & 3.9 & .70 \\
\hline Ob-Gyn & 3.2 & 3.3 & .61 \\
\hline \multicolumn{4}{|l|}{$\mathbf{I R I}^{\mathbf{b}}$} \\
\hline Full & 19.9 & 19.5 & .69 \\
\hline FM & 19.0 & 17.7 & .25 \\
\hline Ob-Gyn & 20.7 & 21.0 & .89 \\
\hline \multicolumn{4}{|l|}{ PSS $^{c}$} \\
\hline Full & 21.0 & 21.4 & .86 \\
\hline FM & 19.8 & 19.3 & .88 \\
\hline Ob-Gyn & 21.9 & 22.9 & .73 \\
\hline \multicolumn{4}{|l|}{ MBI 2-Qd } \\
\hline \multicolumn{4}{|l|}{$\mathbf{Q 1}^{\mathbf{e}}$} \\
\hline Full & 4.1 & 4.0 & .82 \\
\hline FM & 4.3 & 4.0 & .58 \\
\hline Ob-Gyn & 3.9 & 4.0 & .73 \\
\hline \multicolumn{4}{|l|}{$\mathbf{Q}^{\mathbf{f}}$} \\
\hline Full & 2.5 & 3.4 & .08 \\
\hline FM & 2.2 & 3.0 & .34 \\
\hline Ob-Gyn & 2.8 & 3.8 & .17 \\
\hline \multicolumn{4}{|l|}{ TOTAL } \\
\hline Full & 6.6 & 7.4 & .20 \\
\hline FM & 6.5 & 7.0 & .67 \\
\hline Ob-Gyn & 6.6 & 7.8 & .20 \\
\hline
\end{tabular}

Abbreviations: M, questionnaire means; MAAS, Mindful Attention Awareness Scale; IRI, Interpersonal Reactivity Index; PSS, Perceived Stress Scale; MBI, Maslach Burnout Inventory; FM, family medicine; Ob-Gyn, obstetrics and gynecology.

${ }^{a}$ Mindfulness Attention Awareness Scale - Average adult community score $=4.2$

${ }^{\mathrm{b}}$ Interpersonal Reactivity Index-perspective Taking/Empathy Scale; Average college student=16.8-18.0

'Perceived Stress Scale - 0-13 Low Stress; 14-26 Moderate; 27-40 High

${ }^{\mathrm{d}}$ Maslach Burnout Inventory: 0-Never; 1-A few times a year; 2-Once a month; 3-A few times a month; 4-Once a week; 5-A few times a week; 6-Everyday

e Emotional exhaustion question: "I feel burned out from my work."

f Depersonalization question: "I have become more callous toward people since I took this job."

in stress for those who did not $(F[1$, $12]=2.99, P=.11$; Figure 2 ).

\section{Qualitative Surveys}

Figure 3 highlights the exercises residents found most useful. Residents enjoyed the camaraderie, having a safe space to share, and the the current research on mind-body medicine to guide patients, only $29 \%$ felt they knew much about this.

\section{Discussion}

This study highlights the positive benefits a brief training for resident physicians can have over a training year. Similar to MGH, we found stability in perceived stress and empathy from fall to spring. This is encouraging given research shows that empathy typically decreases and perceived stress rises over the course of medical training., ${ }^{3,22}$

While MGH found increased depersonalization and emotional exhaustion from June to January, we found stability from fall to spring, perhaps because we combined years of residency and/or administered posttests in May. The optional texting between sessions had a positive impact as well: those who elected to receive texts had greater mindful attention awareness and tended toward lower stress by spring, the opposite for those who did not receive them. This is striking given our small sample size and suggests potentially powerful effects of using phone text messaging to enhance stress management training. Also of interest, most residents thought it was important to know the current research on mind-body medicine to guide patients, yet only $29 \%$ felt confident in this knowledge. This exemplifies the importance of including scientific evidence related to such practices during medical training. If routinely included in medical education, physicians may be more likely to embrace and utilize such strategies for themselves and refer their patients for the same.

Limitations to this study include the small sample size, lack of randomization/controls, self-selection for texts and reliance on self-report measures. Future studies should include larger randomized trials and deeper exploration of the use of texting in similar context (ie, differences in those who opt in versus those who opt out). 
Figure 1: Interaction Shows Pre to Post Changes in Mindful Attention Awareness Affected by Whether Resident Received Texts or Not $(F[1,12]=5.94, P=.03$ )

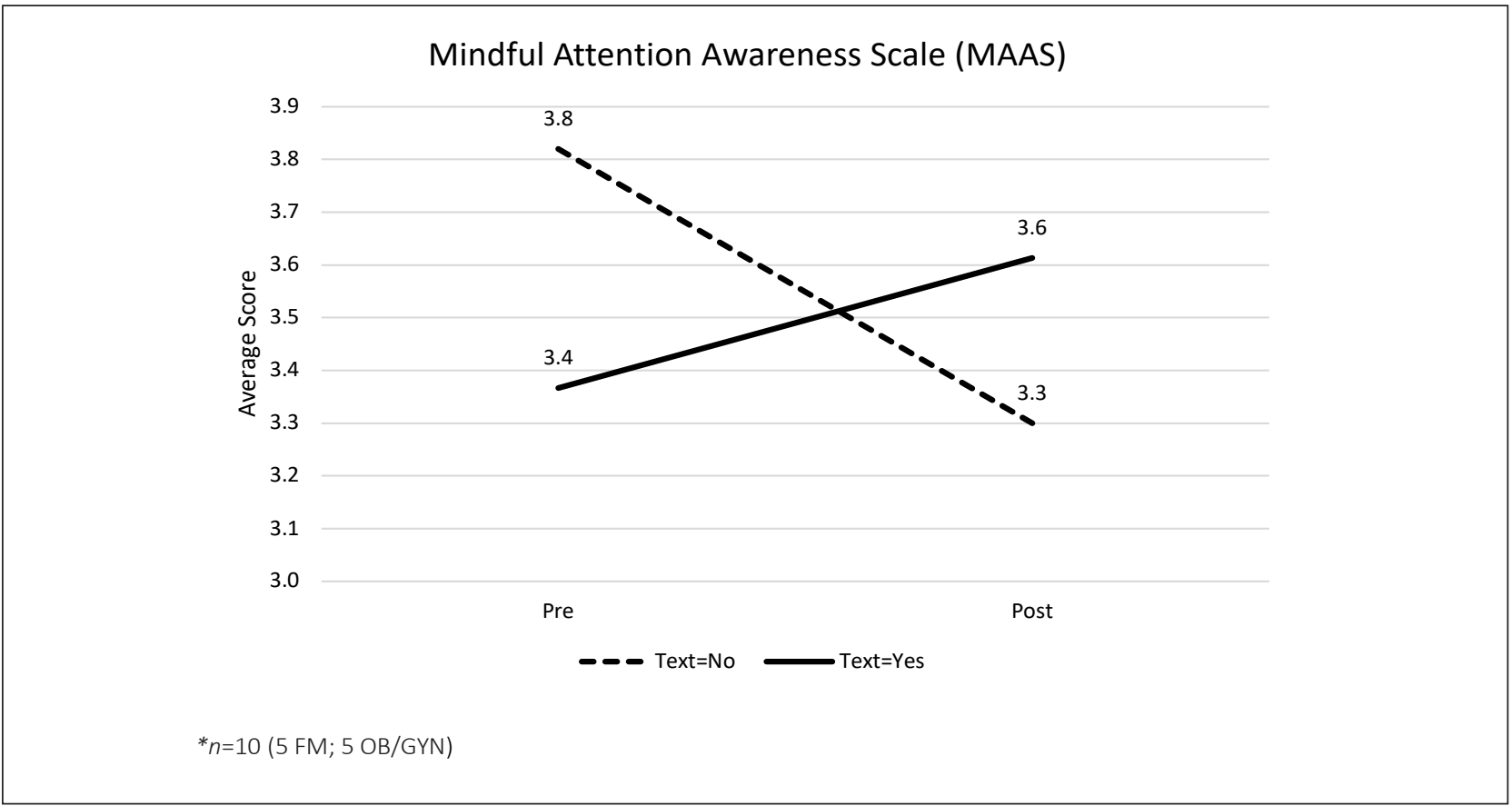

Figure 2: Interaction Shows Pre to Post Changes in Perceived Stress May Be Affected by Whether Resident Received Texts or Not $(F[1,12]=2.99, P=.11)$

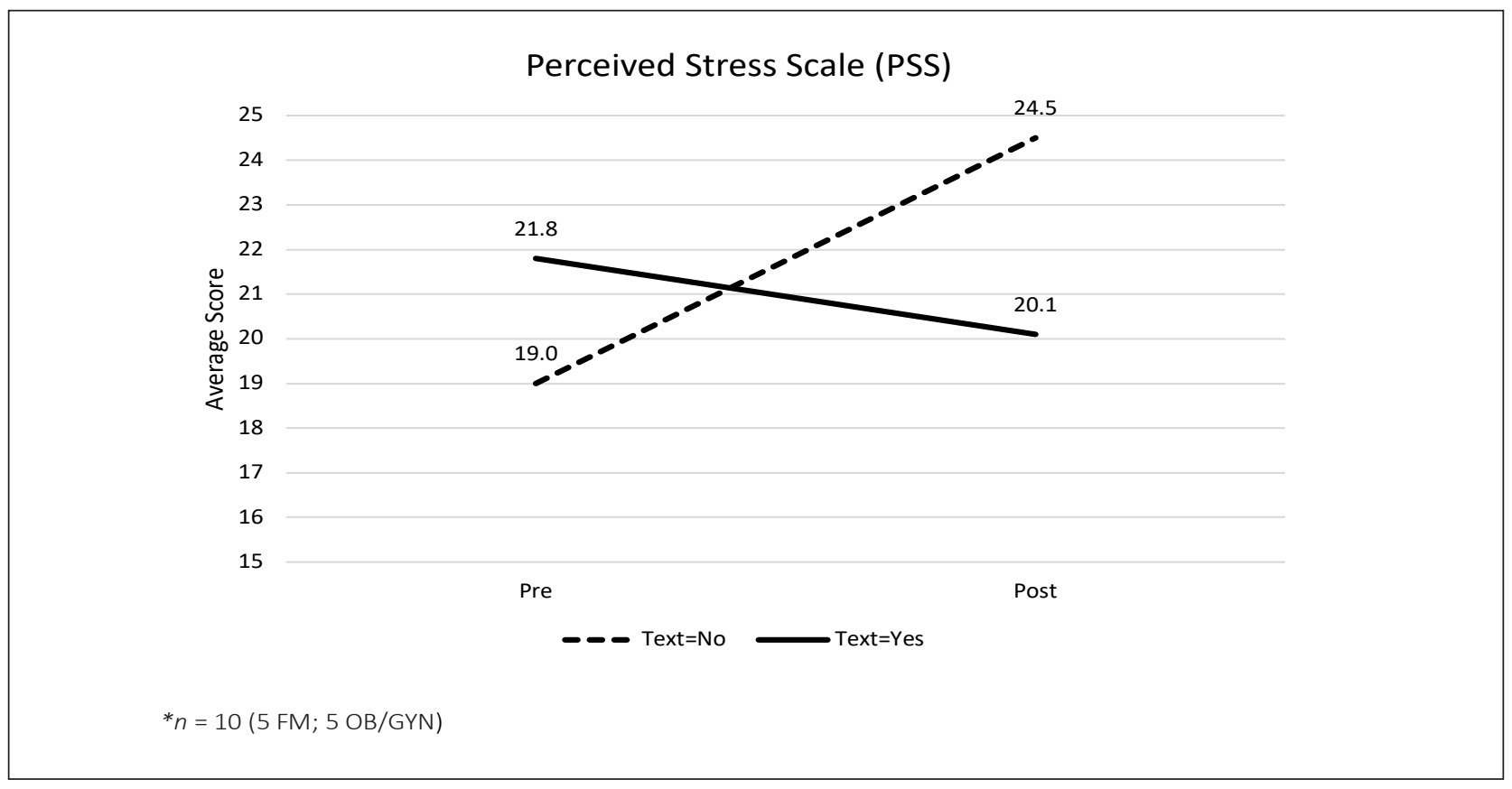


Figure 3: Exercises Residents Found Most Useful and Were Most Likely to Use in the Future Average Score Rated From 1=Strongly Disagree to 5=Strongly Agree

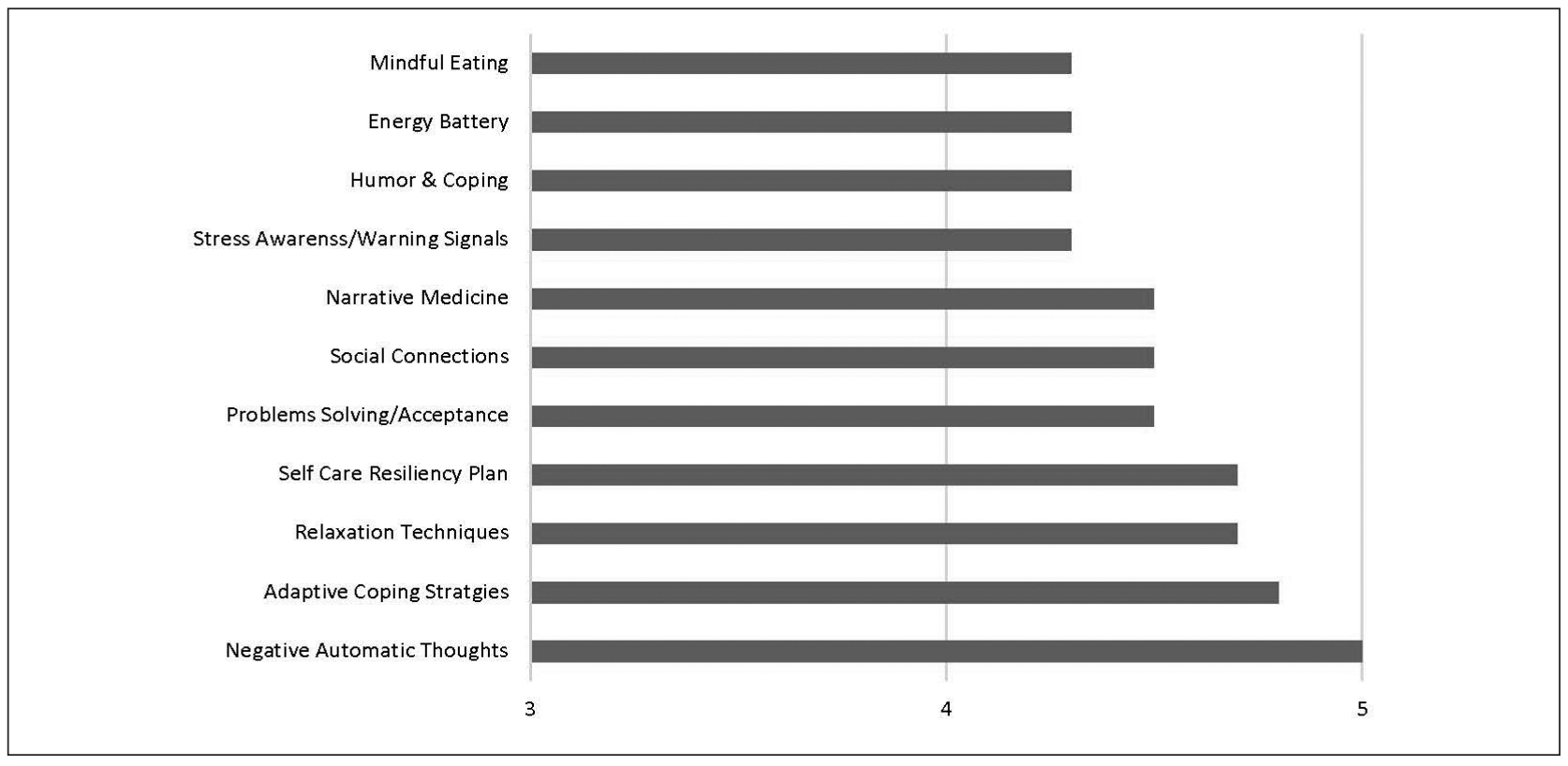

In summary, a relatively inexpensive, brief, stress management training is shown to have the potential to offset some of the negative trends associated with resident burnout. In addition, phone texting seems to have strong potential to enhance such trainings. While some of the negative consequences of burnout may be inevitable during residency training, short programs like this may serve to preserve some of the more critical features of best medical practice, including mindful awareness and empathy.

ACKNOWLEDGMENTS: The authors thank the Departments of Family Medicine and Obstetrics and Gynecology at the University of Vermont Larner College of Medicine. This study was funded through the Frymoyer Scholars Program and the John W. and Nan P. Frymoyer Fund for Medical Education. The authors extend a special thanks to resident physicians Johanna Kelley, MD, and Kelly Brooks, MD, for their help with the project, Luke Hebert and Lise Vance for their administrative assistance, and Alan Howard for statistical support.

FUNDING: This study was funded through the Frymoyer Scholars Program and the John W. and Nan P. Frymoyer Fund for Medical Education.
PRESENTATIONS: This study was previously presented as follows:

Nathan J, McCray L, Feldman N. Stress Management and Resiliency Training for Residents (SMART-R) in Family Medicine (FM) and Obstetrics and Gynecology (ObGyn) Residency Programs at the University of Vermont Medical Center (UVMMC). Poster presentation at the International Conference on Physician Health, Toronto Canada, October 2018.

McCray L, Nathan J, Feldman N, Menezes K, Kelley J, Brook K. Stress Management and Resiliency Training for Residents (Preliminary Findings). Poster presented at the American Academy of Family Physicians, PDW and RPS Residency Education Symposium, Kansas City, MO, March 25, 2018.

Nathan J, McCray L, Feldman N, Menezes K, Kelley J, Brooks K. Stress Management and Resiliency Training for Residents (SMART-R) in OB-GYN \& Family Medicine Residency Programs. Poster presented at the GME Recognition Scholarly Activity Poster Presentation, University of Vermont, February 2018.

Nathan J, McCray L, Feldman N, Menezes K, Kelley J, Brooks K. Stress Management and Resiliency Training for Residents (SMART-R) in Ob-Gyn and Family Medicine Residency Programs at the University of Vermont Medical Center (Preliminary Results). Poster presented at the Larner COM Teaching Academy Snow Season Retreat, Burlington, VT., January 12 , 2018.

Feldman N, Nathan J, McCray L, Menezes K, Kelley J, Brooks K. Stress Management and Resiliency Training for Residents (SMART-R) in Ob-Gyn and Family Medicine Residency
Programs at the University of Vermont Medical Center (Preliminary Results). Poster presented at the Council on Resident Education in Obstetrics and Gynecology (CREOG) and Association of Professors of Gynecology and Obstetrics (APGO) Annual Meeting, National Harbor, MD, February/March 2018

CORRESPONDING AUTHOR: Address correspondence to Dr Jane Nathan, Department of Family Medicine, University of Vermont Larner College of Medicine, 235 Rowell, 106 Carrigan Drive, Burlington, VT 05405. 802-656-4330. Fax: 802-656-3353. jane.nathan@med.uvm.edu.

\section{References}

1. Dyrbye LN, West CP, Satele D, et al. Burnout among U.S. medical students, residents, and early career physicians relative to the general U.S. population. Acad Med. 2014;89(3):443-451. doi:10.1097/ACM.0000000000000134

2. Maslach C. Burned-out. Can J Psychiatr Nurs. 1979 Nov-Dec;20(6):5-9.

3. Wilkinson H, Whittington R, Perry L, Eames C Examining the relationship between burnout and empathy in healthcare professionals: A systematic review. Burn Res. 2017;6:18-29. doi:10.1016/j.burn.2017.06.003

4. Panagioti M, Geraghty K, Johnson J, et al. Association between physician burnout and patient safety, professionalism, and atient satisfaction: a systematic review and meta-analysis. JAMA Intern Med. 2018;178(10):1317-1331. doi:10.1001/jamainternmed.2018.3713 
5. West CP, Tan AD, Habermann TM, Sloan JA, Shanafelt TD. Association of resident fatigue and distress with perceived medical errors. JAMA. 2009;302(12):1294-1300. doi:10.1001/ jama.2009.1389

6. Shanafelt TD, Bradley KA, Wipf JE, Back $\mathrm{AL}$. Burnout and self-reported patient care in an internal medicine residency program. Ann Intern Med. 2002;136(5):358-367. doi:10.7326/0003-4819-136-5-200203050-00008

7. Koutsimani P, Montgomery A, Georganta K. The relationship between burnout, depression, and anxiety: a systematic review and meta-analysis. Front Psychol. 2019;10:284. doi:10.3389/fpsyg.2019.00284

8. Dyrbye LN, Thomas MR, Massie FS, et al. Burnout and suicidal ideation among U.S. medical students. Ann Intern Med. 2008;149(5):334-341. doi:10.7326/0003-4819149-5-200809020-00008

9. Accreditation Council for Graduate Medical Education. ACGME Common Program Requirements: Residency, 2018. Chicago: ACGME; 2018.

10. Busireddy KR, Miller JA, Ellison K, Ren V, Qayyum R, Panda M. Efficacy of interventions to reduce resident physician burnout: a systematic review. J Grad Med Educ. 2017;9(3):294301. doi:10.4300/JGME-D-16-00372.1

11. Schroeder DA, Stephens E, Colgan D, Hunsinger M, Rubin D, Christopher MS. A brief mindfulness-based intervention for primary care physicians: a pilot randomized controlled trial. Am J Lifestyle Med. 2016;12(1):83-91. doi:10.1177/1559827616629121
12. Krasner MS, Epstein RM, Beckman H, et al. Association of an educational program in mindful communication with burnout, empathy, and attitudes among primary care physicians. JAMA. 2009;302(12):1284-1293. doi:10.1001/jama.2009.1384

13. Bentley PG, Kaplan SG, Mokonogho J. Relational mindfulness for psychiatry residents: a pilot course in empathy development and burnout prevention. Academic psychiatry: the journal of the American Association of Directors of Psychiatric Residency Training and the Association for Academic Psychiatry. 2018;42:668-73. doi:10.1007/s40596-018-0914-6

14. Runyan C, Savageau JA, Potts S, Weinreb L. Impact of a family medicine resident wellness curriculum: a feasibility study. Med Educ Online. 2016;21(1):30648. doi:10.3402/meo. v21.30648

15. Verweij H, van Ravesteijn H, van Hooff MLM, Lagro-Janssen ALM, Speckens AEM. Mindfulness-based stress reduction for residents: a randomized controlled trial. J Gen Intern Med. 2018;33(4):429-436. doi:10.1007/s11606017-4249-x

16. Chaukos D, Chad-Friedman E, Mehta DH et al. SMART-R: A prospective cohort study of a resilience curriculum for residents by residents. Academic psychiatry: The Journal of the American Association of Directors of Psychiatric Residency Training and the Association for Academic Psychiatry. 2018;42:78-83. doi:10.1007/s40596-017-0808-z
17. Wen L, Sweeney TE, Welton L, Trockel M, Katznelson L. Encouraging mindfulness in medical house staff via smartphone app: a pilot study. Academic Psychiatry: The Journal of the American Association of Directors of Psychiatric Residency Training and the Association for Academic Psychiatry. 2017;41:64650. doi:10.1007/s40596-017-0768-3

18. Brown KW, Ryan RM. The benefits of being present: mindfulness and its role in psychological well-being. J Pers Soc Psychol. 2003;84(4):822-848. doi:10.1037/00223514.84.4.822

19. Cohen S, Kamarck T, Mermelstein R. A global measure of perceived stress. J Health Soc Behav. 1983;24(4):385-396. doi:10.2307/2136404

20. S K. Critical synthesis package: interpersonal reactivity index (IRI). MedEdPORTAL. 2013;9:9596.

21. West CP, Dyrbye LN, Satele DV, Sloan JA, Shanafelt TD. Concurrent validity of singleitem measures of emotional exhaustion and depersonalization in burnout assessment. J Gen Intern Med. 2012;27(11):1445-1452. doi:10.1007/s11606-012-2015-7

22. Bellini LM, Baime M, Shea JA. Variation of mood and empathy during internship. JAMA. 2002;287(23):3143-3146. doi:10.1001/ jama.287.23.3143 